\title{
Discriminating transplanted and direct seeded rice using Sentinel-1 intensity data
}

\author{
Vidya Nahdhiyatul Fikriyah ${ }^{\mathrm{a}, *}$, Roshanak Darvishzadeh $^{\mathrm{a}}$, Alice Laborte ${ }^{\mathrm{b}}$, Nasreen Islam Khan ${ }^{\mathrm{b}}$, \\ Andy Nelson ${ }^{\mathrm{a}}$ \\ ${ }^{\text {a }}$ Faculty of Geo-Information and Earth Observation (ITC), University of Twente, Enschede, 7500, AE, the Netherlands \\ ${ }^{\mathrm{b}}$ International Rice Research Institute, DAPO Box 7777, Metro Manila 1301, Philippines
}

A R T I C L E I N F O

\section{Keywords:}

Transplanting

Direct seeding

Rice

SAR

Sentinel-1

Philippines

\begin{abstract}
A B S T R A C T
Improved rice crop and water management practices that make the sustainable use of resources more efficient are important interventions towards a more food secure future. A remote sensing-based detection of different rice crop management practices, such as crop establishment method (transplanting or direct seeding), can provide timely and cost-effective information on which practices are used as well as their spread and change over time as different management practices are adopted. Establishment method cannot be easily observed since it is a rapid event, but it can be inferred from resulting observable differences in land surface characteristics (i.e. field condition) and crop development (i.e. delayed or prolonged stages) that take place over a longer time. To examine this, we used temporal information from Synthetic Aperture Radar (SAR) backscatter to detect differences in field condition and rice growth, then related those to crop establishment practices in Nueva Ecija (Philippines). Specifically, multi-temporal, dual-polarised, C-band backscatter data at 20m spatial resolution was acquired from Sentinel-1A every 12 days over the study area during the dry season, from November 2016 to May 2017. Farmer surveys and field observations were conducted in four selected municipalities across the study area in 2017, providing information on field boundaries and crop management practices for 61 fields. Mean backscatter values were generated per rice field per SAR acquisition date. We matched the SAR acquisition dates with the reported dates for land management activities and with the estimated dates for when the crop growth stages occurred. The Mann-Whitney U test was used to identify significant differences in backscatter between the two practices during the land management activities and crop growth stages. Significant differences in cross-polarised, co-polarised and band ratio backscatter values were observed in the early growing season, specifically during land preparation, crop establishment, rice tillering and stem elongation. These findings indicate the possibility to discriminate crop establishment methods by SAR at those stages, suggesting that there is more opportunity for discrimination than has been presented in previous studies. Further testing in a wider range of environments, seasons, and management practices should be done to determine how reliably rice establishment methods can be detected. The increased use of dry and wet direct seeding has implications for many remote sensing-based rice detection methods that rely on a strong water signal (typical of transplanting) during the early season.
\end{abstract}

\section{Introduction}

Food security has become a fundamental issue due to the rapid increase in world population and higher demand for food. Rice is a key staple food consumed by more than half of the world's population (Chauhan et al., 2015). As a consequence, rice production systems must boost production to meet global food demand (Ray et al., 2012). A sustainable increase in rice production is challenged by rural to urban labour migration, agricultural land conversion, pests and diseases, the high cost of labour and inputs, abiotic stresses such as drought, submergence, cold and heat, and competition for water resources (FAO, 2014). The diversity of rice-growing environments (irrigated, rainfed lowland, upland and deep-water) results in different levels of natural resource availability (i.e. water and soil fertility) and different levels of exposure to yield-limiting and yield-reducing factors. This leads to different management approaches to create favourable rice-growing

\footnotetext{
* Corresponding author.

E-mail addresses: vidya.n.fikriyah@ums.ac.id (V.N. Fikriyah), r.darvish@utwente.nl (R. Darvishzadeh), a.g.laborte@irri.org (A. Laborte), nasreenikhan2018@gmail.com (N.I. Khan), a.nelson@utwente.nl (A. Nelson).
} 
conditions (Bouman et al., 2007). Improvements in crop and water management practices are therefore an important component of agronomic and environmental sustainability (Bégué et al., 2018) and providing information on management practice is a viable strategy to optimise the use of the limited environment and socio-economic resources. Such information is also critical to understand the current status of the rice crop because farmers may change their practices over time as they adapt to new situations or opportunities. Therefore, accurate temporal information on rice management practices can support decision-makers in optimising the allocation of government investments in agriculture to sustainably increase farmer profit and production efficiency while minimising or reducing environmental impacts.

In comparison to traditional field data collection, remote sensing offers a great opportunity to obtain such temporal information. Many studies have shown the use of remote sensing data to retrieve rice-related information, highlighting the complementarity of remote sensing approaches to conventional approaches (survey and statistical methods) for improving temporal (Zhang et al., 2015) as well as spatial information on rice crops (Xiao et al., 2006; Inoue and Sakaiya, 2013; Gumma et al., 2014). While remote sensing data can be acquired with passive and active sensors, monitoring rice growing areas using passive sensors is mainly limited by regular and pervasive cloud cover in major rice-growing areas (Nguyen et al., 2015). Active sensors, such as Synthetic Aperture Radar (SAR), overcome this limitation and many studies have extensively demonstrated the potential of SAR for crop mapping and monitoring at different levels of detail (Kuenzer and Knauer, 2013; Nelson et al., 2014; Mosleh et al., 2015; Dong and Xiao, 2016; McNairn and Shang, 2016).

Rice has a unique temporal pattern in backscatter throughout its growth which comes from the interaction between SAR properties (band, polarisation, and incident angle) with rice canopy structure, soil, and surface and canopy water content (Le Toan et al., 1997; Chakraborty et al., 2005; McNairn and Shang, 2016). These interactions can be explained by three main scattering mechanisms: the surface scattering from the ground, the direct-volume scattering from the rice canopy, and multiple scattering (double-bounce) from the interaction between the rice canopy and the ground surface (Bouvet and Le Toan, 2011; Koppe et al., 2013). Previous studies on rice backscatter signatures from X, C, and L-band SAR demonstrated that higher frequencies have weaker penetration capability, and therefore the backscatter contains less information on volumetric features within the canopy (such as leaf area index or LAI), while lower frequencies interact more with underlying soil and water (Inoue et al., 2002). The stronger penetration capability of lower frequencies are useful for rice phenology retrieval (Lopez-Sanchez et al., 2014), and the backscatter from C-band has been found to be consistently correlated with LAI throughout crop growth stages (Inoue et al., 2014). The interaction between the SAR signal and the rice crop also depends on the polarisation (Koppe et al., 2013; Hoang et al., 2016). McNairn and Brisco (2004) summarized the applications of C-band SAR such as JERS-1, RADARSAT-1, and ERS-1/2 for agriculture, and suggested the use of multi-polarised data to gain more information from the crop. A co-polarised signal like $\mathrm{VV}$ is particularly sensitive to the vertical orientation of leaves (Le Toan et al., 1997), while a cross-polarised signal has a stronger correlation to biomass and LAI resulting from the volume scattering within crop canopy (McNairn and Brisco, 2004; Inoue et al., 2014). A few studies have also used polarisation ratios. For instance, Sarabandi et al. (1991) used VV/HH and VH/VV ratios and showed their relationship with soil moisture and roughness, respectively, while Bouvet et al. (2009) used temporal change in the HH/VV ratio to develop a rice crop mapping technique.

Although many studies have used SAR for rice crop mapping (Choudhury and Chakraborty, 2006; Bouvet and Le Toan, 2011; Chen et al., 2011) and monitoring (Kurosu et al., 1995; Shao et al., 2001; Lopez-Sanchez et al., 2012; Koppe et al., 2013), there has been little work on detecting rice crop management practices due to the difficulty to directly observe these and their variation in practices that can occur from field to field. In the Philippines, rice is cultivated in a range of environments, with different cropping intensities, water management practices, as well as dates and methods of crop establishment (Asilo et al., 2014; Nelson et al., 2014; Setiyono et al., 2017). The detection of these different practices, however, can be derived by observing differences in environmental condition, crop development stages and their relationship with the observed SAR backscatter.

Transplanting (TP) and direct seeding (DS) are two common methods of rice establishment (Chauhan et al., 2015). TP is more common in irrigated and rainfed lowland ecosystems (Singh et al., 2008) where there is sufficient water. In TP, seeds are normally germinated in the nursery for 2-3 weeks before they are manually or mechanically transplanted into the main fields (IRRI, 2007a; Sangeetha and Baskar, 2015). In DS, seeds are sown on the soil surface, and this can be practised in rainfed, deep-water, and irrigated systems (Pandey et al., 2000). Sowing can be done manually (hand broadcasting the seeds) or mechanically (using a drum seeder or seed drill, for example). DS rice matures up to seven to ten days faster than TP rice (Pandey et al., 2000; Farooq et al., 2011; Sudhir-Yadav et al., 2014) due to the lack of transplanting shock (Yoshida, 1981). DS can be further classified into wet direct seeding (WDS) or dry direct seeding (DDS). WDS requires seeds that are pre-germinated for $24-48 \mathrm{~h}$ before broadcasting or drilling seeds into the mud with a drum seeder. In DDS, un-germinated seeds are sown (broadcasted, drilled or dibbled) on dry, prepared soil that is ploughed or harrowed afterwards (IRRI, 2007b; Singh et al., 2008). DDS is practised traditionally in rainfed ecosystems in most Asian countries but is gaining importance in irrigated areas where water is becoming scarce (Kumar and Ladha, 2011).

The choice of establishment method is influenced by environmental and socio-economic factors. Areas with low wages (high labour supply) and sufficient irrigation water typically favour TP because of higher yields due to better weed control (Chauhan et al., 2015; Singh et al., 2011). In contrast, DS is prevalent in labour- and water-scarce regions (Kumar and Ladha, 2011). In addition to rainfall distribution, the position of the field in the toposequence also contributes to spatial variations in adoption of crop establishment method (Pandey et al., 2012). DS has been spreading in tropical rice areas of Asia replacing TP, the more traditional way of crop establishment (Pandey et al., 2012). In the predominantly irrigated rice areas of Central Luzon, Philippines, farmers started adopting DSR beginning in the 1980s. The proportion of DS rice reached $22 \%$ in the wet season of 1990 and $71 \%$ in the dry season of 1991 , then eventually dropped to $30 \%$ and $8 \%$ in the dry and wet seasons, respectively, of 2011 (Moya et al., 2015). In Northeast Thailand, DS (specifically DDS) rice increased from 25\% in 1996 to $38 \%$ in 2009 (Pandey et al., 2012). Considerable annual fluctuations were also observed as farmers switched from DS to TP depending on rainfall, the build-up of weeds and short-term changes in rural labour supply (Pandey et al., 2012). In addition to labour- and water- savings, DS reduces methane emissions in rice, reduces the cost of cultivation, and allows timely planting of a subsequent crop, and hence is expected to further expand as labour and water costs increase in future, and improved varieties and crop management practices become available making DS more attractive to farmers (Kumar and Ladha, 2011). The differences in crop establishment practices in terms of presence and duration of water in the fields, water depth, rice canopy structure and growth duration can have a direct effect on the SAR backscatter (Chakraborty et al., 1997; Lam-Dao et al., 2009; Nelson et al., 2014).

Spatial and temporal information on establishment methods can improve the accuracy of remote sensing-based rice crop growth monitoring, and yield estimation since crop establishment method affects water use, weed presence, and incidence of disease (Singh et al., 2011; Chauhan et al., 2015; Setiyono et al., 2017). The higher plant density in DS makes the disease outbreak more severe (Pandey et al., 2000), meaning that different crop management practices can result in different crop health management issues. On the other hand, DS is widely 

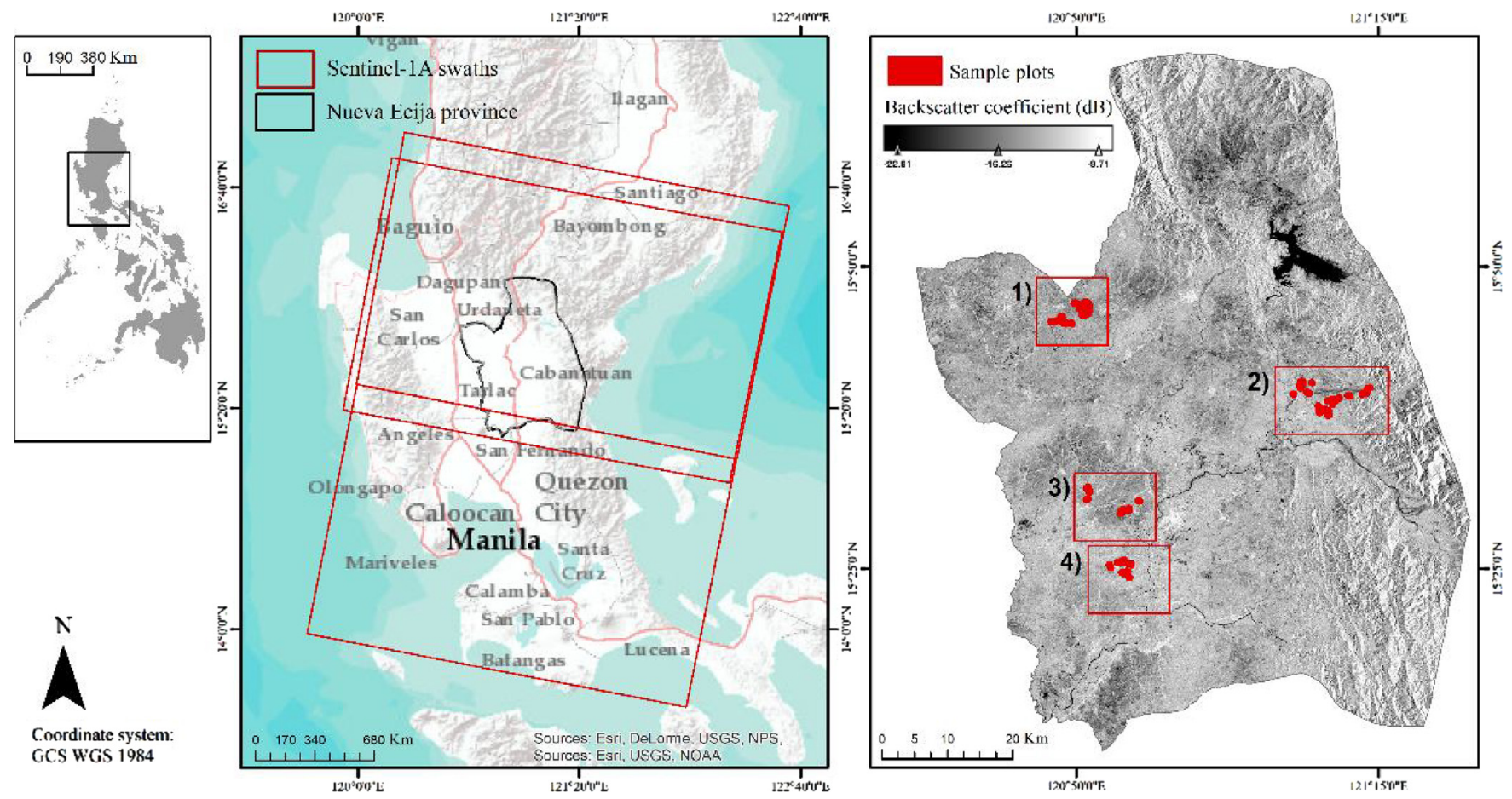

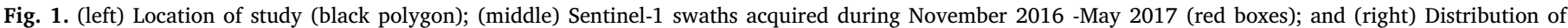

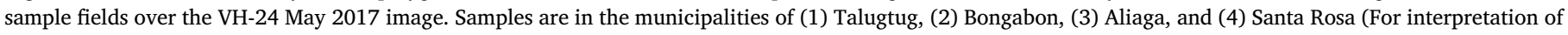
the references to colour in this figure legend, the reader is referred to the web version of this article).

promoted for its contribution to water conservation and methane emission reduction (IRRI et al., 2018) since drier land preparation results in lower water use than wet-land preparation (puddling and tilling) and the use of nursery beds in TP. Although TP has been the most practised method in Asia (Pandey et al., 2000), even in irrigated fields, where water is much available, farmers may adopt DS to reduce their labour cost and water use (Bouman et al., 2007). Where and how rapidly these changes are occurring is poorly documented. Thus seasonal and spatial information on farmers' crop establishment method is important to understand the patterns of adoption (IRRI et al., 2018). Therefore, a better understanding of the temporal behaviour of backscatter to discriminate between TP and DS is an important contribution to this knowledge gap.

Only a few studies have considered SAR data to distinguish between crop establishment methods. Gumma et al., (2015) demonstrated the use of RISAT-1 (C-band, HH polarisation, and 25-days revisit time) to distinguish TP and DDS rice in India. This study showed that early TP and DDS rice have different backscatter responses during the establishment period. Another study in China by Yang et al. (2014), using quad polarisations of RADARSAT-2 data (C-band, 24-days revisit time), attempted to differentiate transplanted-hybrid rice with direct-seeded Japonica rice and pointed out that seedlings in transplanted rice resulted in higher backscatter compared to direct-sown rice at the moment of rice establishment. A recent study by Yang et al. (2017), using RADARSAT-2 and multispectral HJ-1 A/B data, highlighted that discrimination of TP and DS rice based on their difference in the morphological structure during the initial growth of rice, from seed germination to late elongation stage, can improve the accuracy of phenological estimation.

The above-mentioned platforms have limited acquisition frequency leading to no data for some growth stages (Yang et al., 2014). Images with higher revisit time are needed to fully capture the change in backscatter during the rice growing season and to fully explore the differences between DS and TP rice that may be observable throughout the growing season. Freely accessible Sentinel-1 SAR data from the European Space Agency (ESA) provide a better opportunity for more regular and reliable rice crop mapping and monitoring than other Cband platforms (such as RADARSAT-2 and ENVISAT). The Sentinel-1 A and Sentinel-1B satellites are carrying C-band SAR sensors providing imagery in single ( $\mathrm{VV}$ or $\mathrm{HH})$ and dual polarisations $(\mathrm{VV}+\mathrm{VH}$ or $\mathrm{HH}+\mathrm{HV}$ ) with high temporal resolutions (12 days to 6 days in regions towards the poles) and with a long-term monitoring possibility (European Space Agency (ESA, 2013). To our knowledge, only a few studies have used Sentinel-1 time-series data for rice crop mapping (Chen et al., 2016; Nguyen et al., 2016; Mansaray et al., 2017; Nguyen and Wagner, 2017; Torbick et al., 2017; Clauss et al., 2018) and none of them has applied Sentinel-1 for the detection of rice crop establishment methods. Given that most rice crop mapping algorithms depend on the detection of a strong water signal at the start of the growing season, which is typical of TP rice but not of DS rice, a more comprehensive understanding of the observable differences due to TP and DS would also improve the capability of rice mapping systems.

The detection of rice crop establishment methods using active remote sensing data, particularly dense time-series SAR data has not been investigated. Moreover, the potential of Sentinel-1 data to detect the rice crop establishment methods has not been explored. Therefore, the present study aims to discriminate between TP and DS rice by analysing their temporal backscatter signatures throughout the growing season using multi-temporal Sentinel-1 imagery, field data and farmer survey information.

\section{Materials and methods}

\subsection{Study area}

The study area covers Nueva Ecija province in the eastern part of Central Luzon, Philippines (between $15^{\circ} 10^{\prime} 00^{\prime \prime} \mathrm{N}$ to $16^{\circ} 7^{\prime} 56^{\prime \prime} \mathrm{N}$ and $120^{\circ} 26^{\prime} 50^{\prime \prime}$ E to $121^{\circ} 22^{\prime} 26^{\prime \prime}$ E) (Fig. 1). The region has a dry season from December to April and a wet season from May to November. The maximum rainfall occurs in July and August, the average annual rainfall is $1500 \mathrm{~mm}$, and the average temperature is $27^{\circ} \mathrm{C}$ (Chen et al., 2011). The terrain in the southwestern part of the province (near the 
Pampanga border) is mostly flat while the northeast part close to the mountains of the Sierra Madre is rolling upland.

Nueva Ecija is the top rice growing area in Central Luzon, supplying approximately $8 \%$ of national rice production from 1990 until 2013, and it is often referred to as the 'Rice Bowl of the Philippines' (Bordey et al., 2016). Irrigated lowland and rainfed rice fields are two major rice ecosystems occupying 138,157 ha $(78 \%)$ and 38,387 ha $(22 \%)$, respectively. The Upper Pampanga River Integrated Irrigation System (UPRIIS) supplies water for the irrigated fields (Asilo et al., 2014; Nelson et al., 2014). At the start of the growing season, the land is prepared and flooded by irrigation (or water pump) where standing water is maintained at 2-3 cm level for about 3-7 days or until the land is soft enough for ploughing and establishment. Rice is then cultivated in two planting seasons, by both transplanting and direct seeding in the dry season (December to April) and by transplanting in the wet season (June to October) due to abundant water supply (Asilo et al., 2014; Bordey et al., 2016). In general, 3-4 week old rice seedlings are transplanted in the main field. The most commonly planted varieties have short to medium maturity durations (90-130 days), such as NSIC (National Seed Industry Council) Rc216 (Tubigan 17), Rc222 (Tubigan 18), and Hybrid SL8. Mechanical harvesting is prevalent in both seasons. Ratooning after harvesting is not widely practised in the study area.

\subsection{Data}

\subsubsection{Existing household and rice farm survey datasets}

Farmer survey data from Metrics and Indicators for Tracking in the Global Rice Science Partnership (MISTIG) was provided by the International Rice Research Institute (IRRI). It contained information on farmer household location and farm characteristics. MISTIG was conducted during the dry and wet seasons of the 2013-14 crop year and included information on approximately 1800 farming households in sixty villages in total in the top four rice-producing provinces in the Central Luzon region. We used information on crop establishment methods reported in MISTIG to select villages with a good distribution of TP and DS rice fields for our fieldwork. Although farmer practices can change rapidly, MISTIG was the best available source of contemporary information on crop establishment practices.

\subsubsection{Field data collection and farmer survey}

Data collection was performed during the 2017 wet season to: (i) interview farmers on their management practices in the previous dry season (2016-2017); (ii) record the GPS coordinates of their field boundaries where rice was grown during the dry season; and (iii) note the location of any non-rice objects in the field. Questions on management practice included crop calendar, establishment method, water source (canal irrigation, purely rainfed, or rainfed with supplemental irrigation from water pumps), cropping intensity (single, double, or triple cropping per calendar year), and copping pattern (rice-rice, riceother, other-rice, rice-fallow, and fallow-rice). All participants gave informed oral consent prior to the survey interview and had the option to terminate the interview at any point. GPS coordinates of fields were recorded with approximately $3 \mathrm{~m}$ accuracy using handheld GPS units. Field observations, photos and sketches were used to note the location of nursery seedbeds and any objects that could influence the backscatter within the field, such as trees and pump houses.

Samples were selected purposively based on MISTIG survey data (Table 1). Accordingly, six to eight farmers in the municipality of Aliaga, Bongabon, Santa Rosa, and Talugtug were selected for interview considering variability in the crop establishment methods, accessibility, farmer availability, and time restrictions for the data collection.

In total, 73 farmers were interviewed, and 91 fields were visited in which 61 fields were rice fields in the 2016-2017 dry season (Table 2). Both establishment methods, TP and WDS, were commonly practised in the dry season (29 and 31 fields respectively), while dry direct seeding
Table 1

Rice area and percentage of the transplanted and direct seeded area with number of farmers in selected municipalities in Nueva Ecija during the dry season obtained from MISTIG for field data collection and farmer survey. (source: IRRI-MISTIG, 2013-2014).

\begin{tabular}{|c|c|c|c|c|c|c|}
\hline \multirow[t]{3}{*}{ Municipality } & \multirow{3}{*}{$\begin{array}{l}\text { Rice } \\
\text { area } \\
\text { (ha) }\end{array}$} & \multirow{3}{*}{$\begin{array}{l}\text { Number of } \\
\text { farmers }\end{array}$} & \multicolumn{4}{|c|}{ Crop establishment method } \\
\hline & & & \multicolumn{2}{|c|}{ Transplanting (TP) } & \multicolumn{2}{|c|}{$\begin{array}{l}\text { Direct seeding } \\
\text { (DS) }\end{array}$} \\
\hline & & & rice area & farmer & $\begin{array}{l}\text { rice } \\
\text { area }\end{array}$ & farmer \\
\hline Bongabon & 32 & 32 & $30 \%$ & 9 & $70 \%$ & 23 \\
\hline Talugtug & 35 & 27 & $100 \%$ & 27 & $0 \%$ & 0 \\
\hline Santa Rosa & 149 & 51 & $57 \%$ & 29 & $43 \%$ & 22 \\
\hline Aliaga & 92 & 32 & $56 \%$ & 10 & $44 \%$ & 22 \\
\hline
\end{tabular}

Table 2

Number of rice and non-rice fields visited during the fieldwork (2016-2017 dry season) with the number of fields practising Transplanting (TP), wet direct seeding (WDS), and dry direct seeding (DDS).

\begin{tabular}{lllll}
\hline Crop & $\begin{array}{l}\text { Number of } \\
\text { fields }\end{array}$ & Transplanting (TP) & $\begin{array}{l}\text { Wet direct } \\
\text { seeding (WDS) }\end{array}$ & $\begin{array}{l}\text { Dry direct } \\
\text { seeding (DDS) }\end{array}$ \\
\hline $\begin{array}{l}\text { Rice } \\
\text { Non-rice }\end{array}$ & 61 & $29(47 \%)$ & $31(51 \%)$ & $1(2 \%)$ \\
Total & 91 & & & \\
\hline
\end{tabular}

was only practised in one field and hence was not considered in the rest of analysis.

\subsubsection{Sentinel-1A time-series images}

Sentinel-1 consists of Sentinel-1A and Sentinel-1B constellations providing imagery in every 12 days for each satellite in equatorial area with an increased frequency of observation towards the poles. Both single (VV and $\mathrm{HH}$ ) and dual polarisations (VV $+\mathrm{VH}$ and $\mathrm{HH}+\mathrm{HV}$ ) are available in four modes (Strip map, Interferometric Wide Swath, Extra Wide Swath, and Wave mode) (European Space Agency (ESA, 2013). In this study, we used 26 SAR images covering the period November 2016 to May 2017 that were acquired from the ESA Copernicus Open Access Hub (https://scihub.copernicus.eu/dhus/\#/home). The SAR images were dual polarised (VV + VH) Sentinel-1 A images in Interferometric Wide Swath (IW) mode, at Level-1 and in Ground Range Detected (GRD) format with $20 \mathrm{~m}$ resolution (Table 3). We used only Sentinel-1 A images since the acquisition time gap between Sentinel-1A and Sentinel-1B over the study area was only 2-3 days (based on descending pass images from Sentinel-1A and ascending pass images from Sentinel-1B), and a combination of these would not be suitable for the time series analysis. All pre-processing steps were performed in the (Sentinel Application Platform) SNAP Toolbox version 5.0.

\subsection{Methods}

Fig. 2 gives an overview of data processing and information flow to achieve the aim of the study. The processing steps are explained in detail in the following subsections.

\subsubsection{Sentinel-1 basic pre-processing}

First, a pair of images with the same acquisition date (slices three and four) was assembled into one image to cover the whole Nueva Ecija province. There were 16 images in total (acquired in November 2016January 2017) that needed to be merged (into eight images), while subsequent dates were covered by just one slice. The orbit information of satellite position was updated using the restituted orbit option since this information was available in real-time. Then, images were calibrated to convert the intensity values into sigma nought $\left(\sigma^{\circ}\right)$ and to generate the true SAR backscatter of the objects. Two image stacks were 
Table 3

Specifications of the Sentinel-1 images used in the study (ESA, 2013).

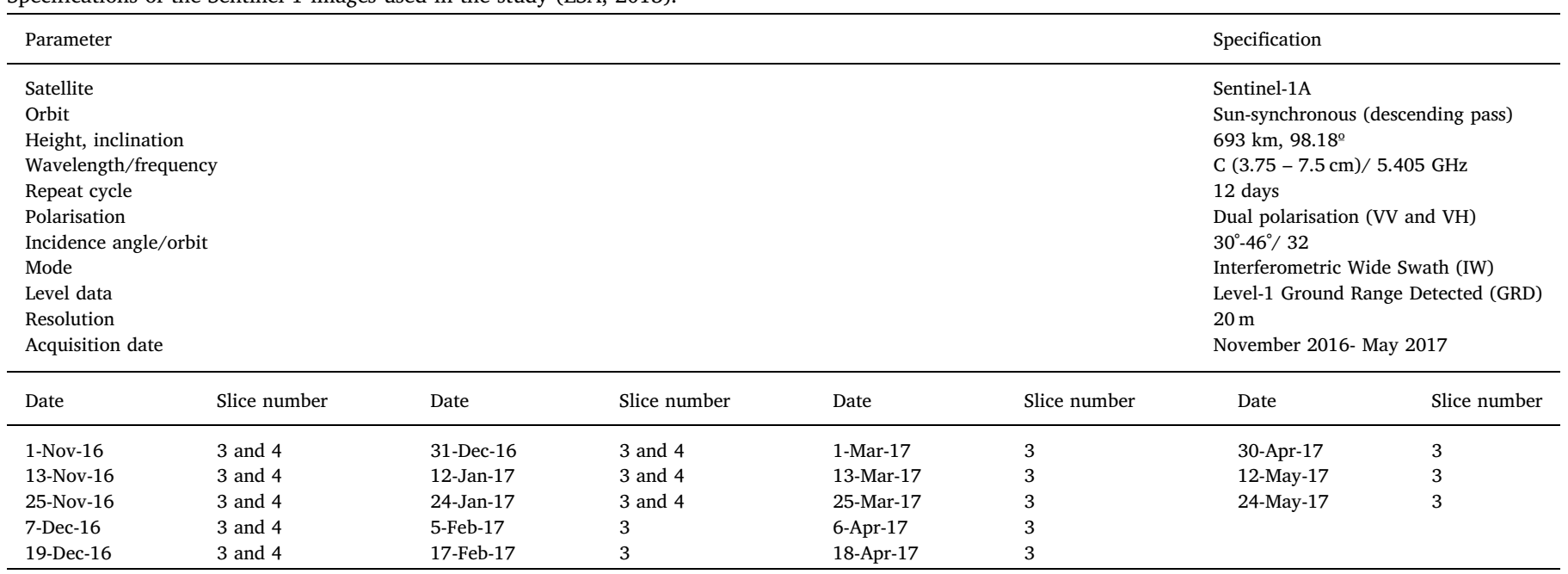

then created for $\mathrm{VV}$ and $\mathrm{VH}$ polarisations, each containing 18 images, and were ordered by observation date. A multi-temporal Refined Lee filter, based on Lavreniuk et al., (2017) was applied to remove speckle noise. The filter is a spatial and temporal filter which minimises the short-term change of backscatter caused by a SAR sensor; therefore, any change in the backscatter is assumed to be due to the change in the object properties in the environment (Nelson et al., 2014; Nguyen and Wagner, 2017). Finally, Range-Doppler Terrain correction was applied to remove the distortion caused by topography and to register the images from the sensor geometry into geographic projection-WGS 1984 using a $90 \mathrm{~m}$ resolution Digital Elevation Model (DEM) from the Shuttle Radar Topography Mission (SRTM).

\subsubsection{Backscatter extraction for land management steps and crop growth} stages in rice growing season

Non-rice objects, such as seedbeds, trees, and pump houses were masked out from the 61 rice field polygons. A $10 \mathrm{~m}$-negative buffer was also applied to avoid disturbance from bunds and adjacent fields with a different practice. This was done for 27 out of 61 polygons, though the negative buffer could not be applied to small and narrow fields. Mean backscatters were then extracted for every polygon and grouped based on crop establishment method. We tested the impact of the negative buffer by running the whole analysis using buffered and non-buffered fields and found no significant difference (results not shown), but in practice, it makes sense to take steps to remove the potential influence of neighbouring fields and bunds wherever possible.

The temporal signatures of TP and WDS rice were analysed across the whole rice growing season. Backscatter was extracted for each land management step (land preparation and flooding), crop establishment, and for selected rice crop stages: tillering and stem elongation, heading and flowering, and maturity. The stages of rice phenological growth were based on a classification developed by IRRI (2007c). Information about the time of land preparation, flooding, crop establishment, the age of seedling, and maturity duration was obtained from the farmer

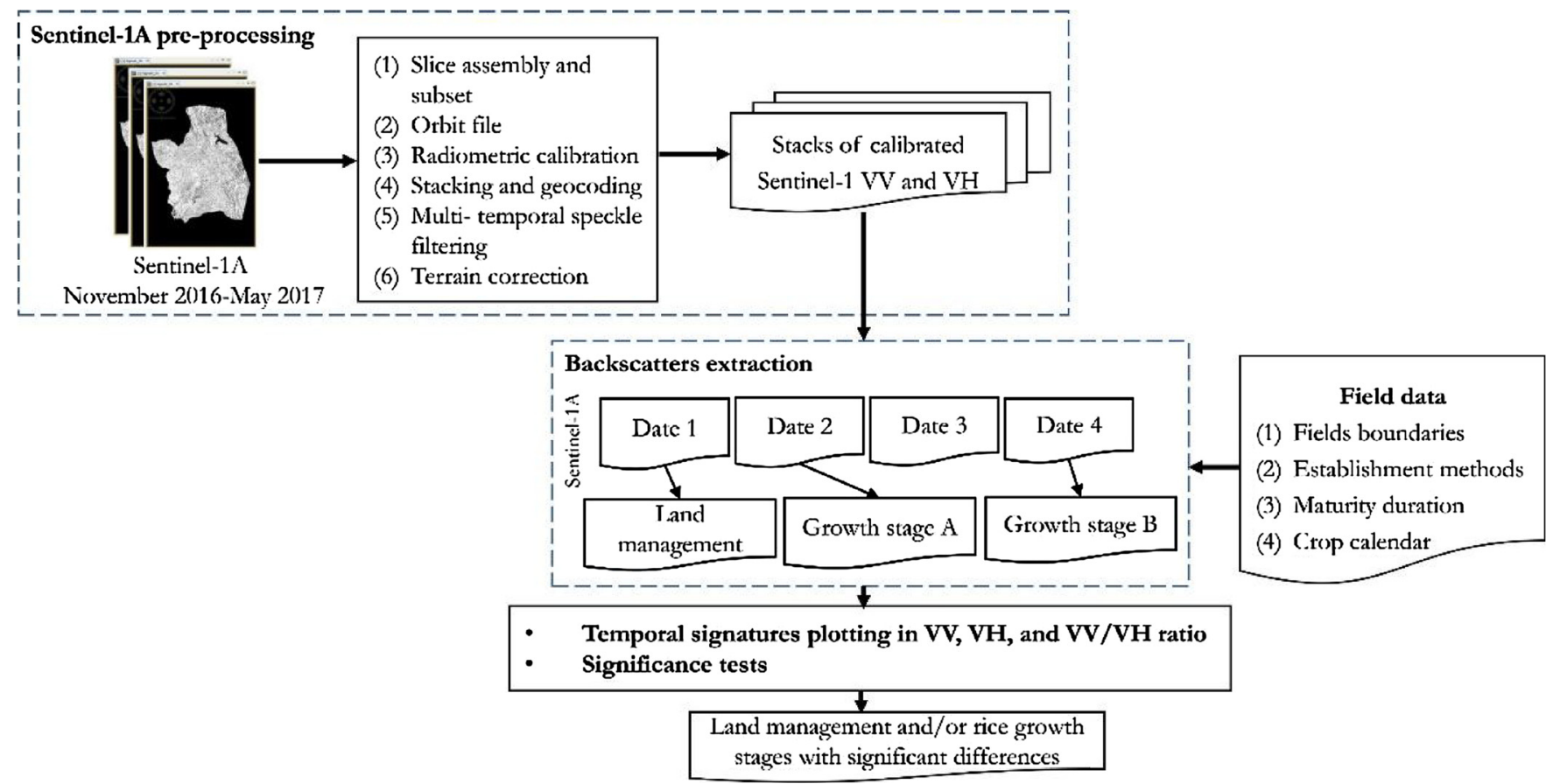

Fig. 2. Flow chart of data processing to extract backscatter signatures for transplanted (TP) and direct seeded (DS) rice. 
questionnaires. Information about the time of land preparation, flooding, and crop establishment was available in either date or week.

The time of tillering and stem elongation, heading and flowering, and maturity stages were estimated based on the establishment date and maturity duration of the variety reported by the farmer. We assumed the following: the vegetative phase, from germination to stem elongation, varies between 30 and 65 days depending on whether the variety was a short or medium duration; the reproductive phase, from panicle initiation to flowering, lasts 35 days; and the duration of the ripening phase, from flowering to maturity, lasts 30 days. We counted forwards from the establishment date and estimated the end dates of each phase based on the above assumptions of their durations for the reported variety. Tillering and stem elongation occur at the end of the vegetative phase, heading and flowering occur at the end of the reproductive phase, and maturity occurs at the end of the ripening phase.

Two adjustments in our calculations were required to estimate the time of tillering and stem elongation (as the late stages of vegetative phase). Our observations focused on the conditions in the rice fields, so the crop condition in the nursery for TP rice was excluded. For TP rice, the duration of the vegetative phase was reduced by the age of seedling since the vegetative phase has started in the nursery and our observations of the vegetative phase begin once the seedling has been transplanted into the rice field. The duration of the vegetative phase for WDS rice was reduced by ten days based on the assumption that DS rice matures faster (tillering earlier) than TP rice (Pandey et al., 2000; Farooq et al., 2011; Sudhir-Yadav et al., 2014).

For the backscatter extraction, we identified which SAR acquisition occurred during or immediately after the land management step (based on the dates reported by farmers for land preparation, flooding, crop establishment, and harvesting) or crop stage (based on estimated dates for tillering and stem elongation, heading and flowering, and maturity as described above). This approach avoids mixing backscatter extracted from different management steps or crop stages due to different crop calendars. Finally, the backscatter values from VV, VH, and the VV/VH ratio were visualised with boxplots and statistically compared to examine the temporal patterns of TP and WDS rice.

\subsubsection{Significance difference test}

The Mann-Whitney U test was performed to determine if there were significant differences in the backscatter between TP and WDS rice. The test is a non-parametric test and is comparable to the t-test, but it does not rely on the assumption of normally distributed data, so it is suitable since our data were not normally distributed (based on a Shapiro-Wilk test). The Mann-Whitney U test compares two independent groups, here the TP and WDS backscatters, by their median (McCrum-Gardner, 2008), which makes it more robust under the non-normality condition. We set $95 \%$ as the confidence level.

\section{Results}

\subsection{Temporal backscatter signatures of TP and WDS rice for each acquisition date}

Fig. 3(A-D) shows the temporal signatures of TP and WDS plotting by image acquisition dates with the information of crop calendar from the farmer's interview during the survey. As can be seen from Fig. 3D, there was a large variation in the start of the dry season across the surveyed fields. Land preparation occurred from early November to the middle of January, followed by flooding and rice establishment until February. As a result, the extracted backscatters from the same date capture different land conditions and rice growth stages, hence making it impossible to directly discriminate differences due to particular land management steps or stages of crop development that would be associated with TP and WDS rice from the temporal backscatter signature.

Field sizes varied from 0.5 to 2 ha, and the average field size was 1.07 ha, based on polygons from GPS locations of the field corner coordinates. The differences in backscatter from 27 fields before and after negative buffering was on average $0.57 \mathrm{~dB}$ in VV and $0.58 \mathrm{~dB}$ in $\mathrm{VH}$.

Furthermore, the direct seeded and transplanted fields are distributed in the central part of the image within different incidence angles $\left(39^{\circ}-42^{\circ}\right.$ ) (Table 4). The row directions of the transplanted fields are also given in Table 5 .

\subsection{Temporal backscatter signatures of TP and WDS rice}

TP and WDS rice temporal signatures were grouped by land management step or crop growth stage, from pre-season (land preparation) to harvesting (Fig. 4A-C). Only the signatures with the assumption of early tillering in WDS rice are shown (results without this assumption are reported in the supplementary materials). The backscatter (dB) of TP and WDS rice appeared similar during the heading-flowering to the harvesting time in both $\mathrm{VV}$ and $\mathrm{VH}$. The highest variations were identified at the early growing season, from land preparation to the tillering-stem elongation stage. In TP rice, $\mathrm{dB}$ values started increasing from when the rice was transplanted until reaching a maximum point at the heading- flowering (VV) and maturity stages (VH). During establishment, it can be seen that the $\mathrm{dB}$ in $\mathrm{VH}$ for TP rice was higher than that of WDS. After transplanting, a slight increase of $\mathrm{VH}$ was also observed at the tillering-stem elongation stage.

The $\mathrm{dB}$ for WDS rice remained relatively stable between the flooding and establishment period. The most striking feature was at the tillering-stem elongation in VV where $\mathrm{dB}$ for WDS was much higher than that of TP. The dB of WDS in VH was also consistently higher after establishment date and throughout the rice growth cycle. The VV/VH ratio showed similar differences between TP and WDS in land preparation, crop establishment, and during tillering-stem elongation. The results for temporal backscatter signatures without the assumption of early tillering in WDS rice are similar in all respects (see supplementary materials), however, when early tillering is not assumed, a slightly greater increase of WDS over TP was observed during tillering-stem elongation in VV.

\subsection{Statistical tests (Mann- Whitney $U$ test)}

The Mann-Whitney U test was used to assess whether there were significant differences between TP and WDS backscatter values. Table 6 gives p-values for the backscatter differences with the assumption of early tillering in the WDS rice. Results for the test without the assumption are shown in the supplementary materials. As Table 6 shows, the backscatter differences between TP and DS at the crop establishment $(\mathrm{VH})$ and tillering-stem elongation stage (VV) were significant. Also, the VV/VH ratio showed significant differences during land preparation, and crop establishment.

\section{Discussion}

\subsection{Temporal backscatter signatures of TP and WDS rice}

Different rice crop establishment methods (transplanting, TP or direct seeding, DS) are adopted as part of a farmer's decision-making process, which is in turn dependent on available resources and environmental conditions, such as water supply and labour availability. These decisions can lead to different challenges for the farmer (i.e. additional weed control when shifting from TP to DS) which may require agronomic advice and education from extension agents in order to achieve optimal and sustainable rice production. Accurate detection of (changes in) crop establishment methods can be incorporated into rice area maps that would guide extension agents on where to provide information to farmers on best management practices. Mapping the spatial patterns of crop establishment is challenging when there is a large variation in the crop calendar from field to field. Given the different 


\section{Crop Establishment Method 追 TP 追 WDS}
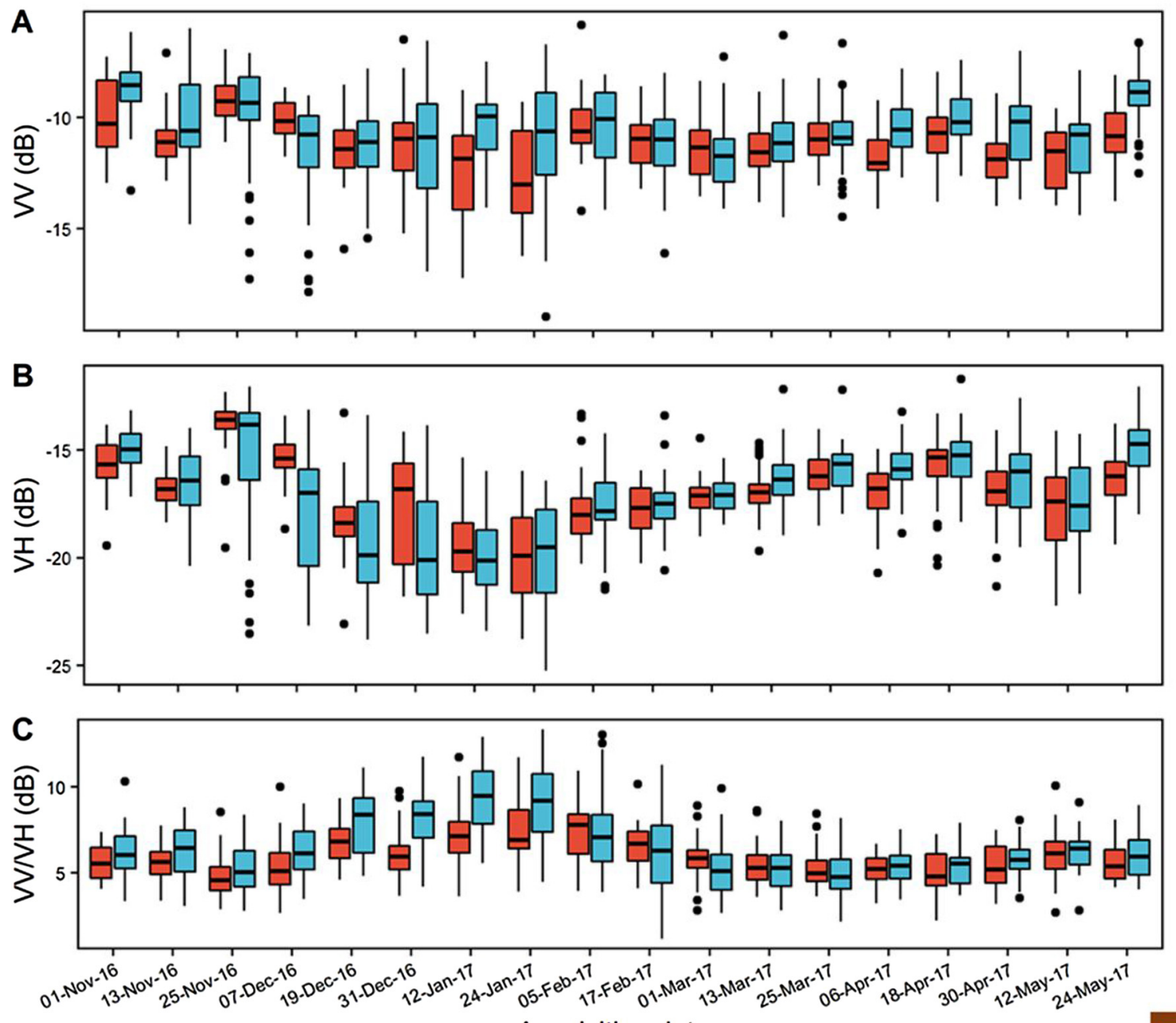

D Acquisition dates

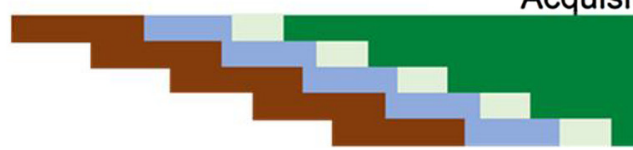

\section{Land preparation Flooding Crop establishment Growing period Harvesting}

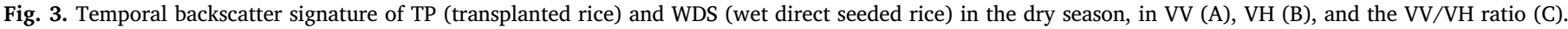
Backscatters were extracted for each field and each acquisition date. Graph D shows the crop calendar in the $2016-2017$ dry season based on farmer responses.

Table 4

Distribution of fields across different incident angles.

\begin{tabular}{llllll}
\hline & \multicolumn{3}{l}{ Incidence angle (degree) } & \\
\cline { 2 - 5 } Crop establishment method & $39^{\circ}$ & $40^{\circ}$ & $41^{\circ}$ & $42^{\circ}$ & Total fields \\
\hline Transplanted (TP) & 2 & 0 & 16 & 11 & 29 \\
Wet Direct Seeding (WDS) & 13 & 1 & 17 & 0 & 31 \\
Dry Direct Seeding (DDS) & 0 & 0 & 1 & 0 & 1 \\
\hline
\end{tabular}

Table 5

Distribution of the row directions of transplanted fields with respect to the North orientation.

\begin{tabular}{llllll}
\hline & \multicolumn{1}{l}{ row direction (degree) } & \\
\cline { 2 - 5 } $\begin{array}{l}\text { Crop establishment } \\
\text { method }\end{array}$ & $0^{\circ}-45^{\circ}$ & $46^{\circ}-90^{\circ}$ & $91^{\circ}-135^{\circ}$ & $136^{\circ}-179^{\circ}$ & $\begin{array}{l}\text { Total } \\
\text { fields }\end{array}$ \\
\hline Transplanted (TP) & 15 & 3 & 1 & 10 & 29 \\
\hline
\end{tabular}

characteristics of land preparation and crop growth in both methods (Pandey et al., 2000; Singh et al., 2008; Farooq et al., 2011; SudhirYadav et al., 2014; Sangeetha and Baskar, 2015) and the sensitivity of SAR to crop development (Le Toan et al., 1997; Chakraborty et al., 2005), it is possible, therefore, to discriminate TP and DS by observing differences in field condition and rice crop growth by SAR only when there is good a priori knowledge of the crop calendar.

Prior studies have used SAR data to observe the temporal backscatter characteristics of TP and DS rice using RISAT-1 data (C-band, HH polarisation, 25-days temporal resolution) (Gumma et al., 2015) and RADARSAT-2 data (C-band, full polarisation, 24-days temporal resolution) (Yang et al., 2014). However, these studies had limited acquisition frequency. Concerning the wide range of dates in the crop calendar in our study area (the range can be up to 2 months), frequent image observation is essential to obtain sufficiently detailed temporal information so that differences in field and crop condition associated with establishment method can be detected. In this study, we analysed the temporal backscatter of TP and WDS rice using Sentinel-1 data (Cband, VV and VH polarisation with 12-days revisit time) and considered the variation in the cropping calendar by relating backscatter values to 


\section{Crop Establishment Method 包 TP 巨 WDS}
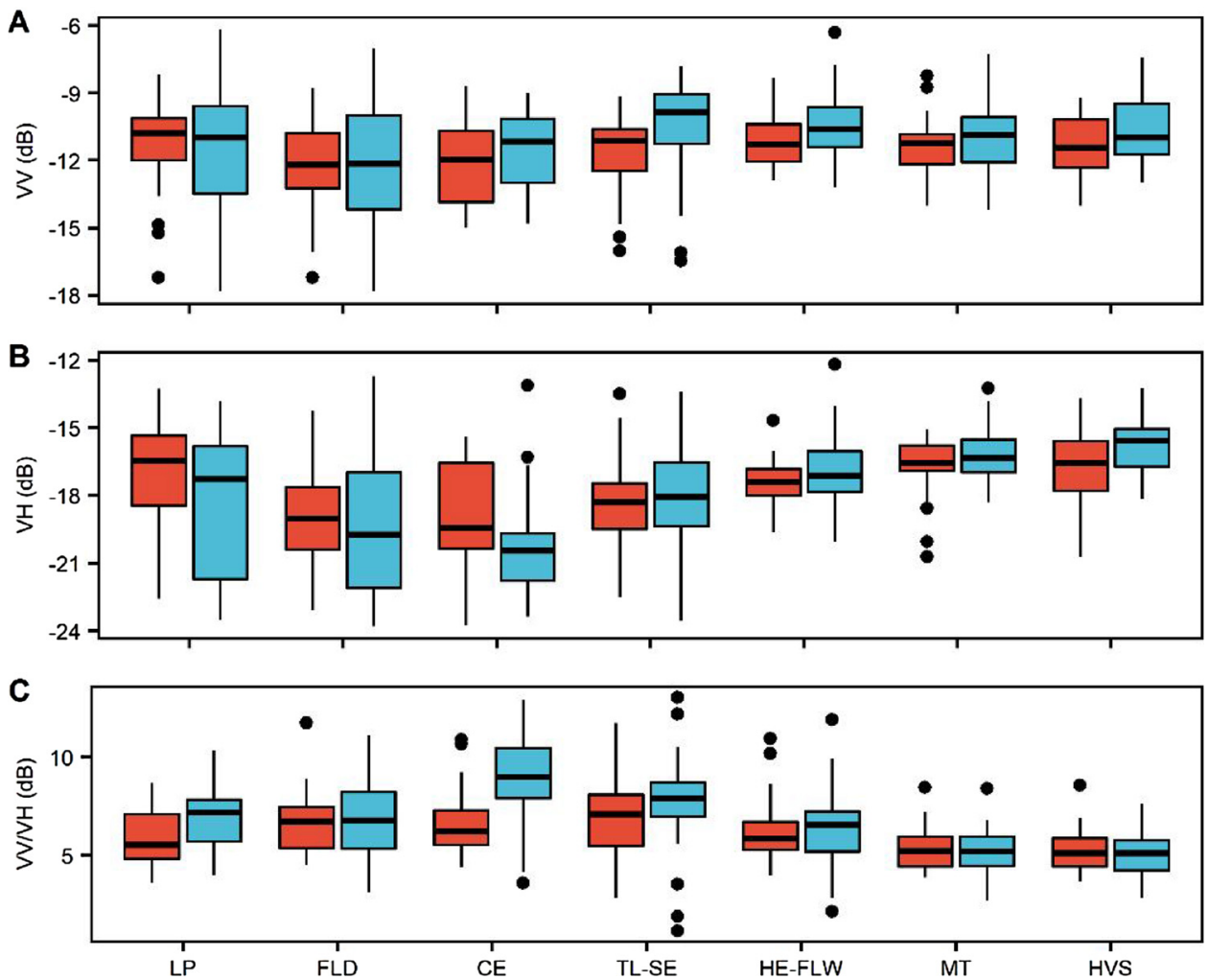

Fig. 4. Temporal backscatter signatures of transplanted rice (TP) and wet direct seeded rice (WDS) in the dry season at $\mathrm{VV}, \mathrm{VH}$ and the $\mathrm{VV} / \mathrm{VH}$ ratio (A-C, respectively). Box plots show the backscatter coefficient $(\mathrm{dB})$ for different land management steps and rice crop stages. LP: land preparation, FLD: flooding, CE: crop establishment, TL-SE: tillering-stem elongation, HE-FLW: heading-flowering, MT: maturity, and HVS: harvesting.
Table 6

p-values between transplanted (TP) and wet direct seeded rice (WDS) from Mann-Whitney U test, with the assumption of early tillering in WDS rice $n$ TP: 29, $n$ WDS: 31.

\begin{tabular}{llll}
\hline & \multicolumn{2}{l}{ Polarisation } & \\
\cline { 2 - 4 } & VV & VH & VV/VH \\
\hline LP & 0.923 & 0.105 & $0.019^{*}$ \\
FLD & 0.947 & 0.853 & 0.520 \\
CE & 0.228 & $0.006^{* * *}$ & $0.000^{* * * * *}$ \\
TL-SE & $0.006^{* * *}$ & 0.311 & 0.119 \\
HE-FLW & 0.119 & 0.171 & 0.559 \\
MT & 0.201 & 0.371 & 0.796 \\
HVS & 0.066 & $0.019^{* *}$ & 0.631 \\
\hline
\end{tabular}

LP: land preparation, FLD: flooding, CE: crop establishment, TL-SE: tilleringstem elongation, HE-FLW: heading- flowering, MT: maturity, and HVS: harvesting.

$$
\begin{aligned}
& * \text { Significant, } \mathrm{p}<0.05 . \\
& * * \quad \text { Significant, } \mathrm{p}<0.01 . \\
& * * * \quad \text { Significant, } \mathrm{p}<0.001 .
\end{aligned}
$$

the reported date of management activities (the dates of land preparation, flooding, and crop establishment from the farmer survey) (Fig. 3) and to the estimated dates of selected growth stages.

As seen in the results (Fig. 4A-C), it is apparent that TP rice had a higher $\mathrm{dB}(\mathrm{VH})$ during rice crop establishment and a lower $\mathrm{dB}(\mathrm{VV})$ during the tillering-stem elongation stage as compared to WDS rice. These findings may be explained by the fact that TP rice is established as 3-4 week old seedlings. The presence of young seedlings in the field results in a higher $\mathrm{dB}$ of TP rice at the time of crop establishment. A slower increase in $\mathrm{dB}$ after transplanting (in the tillering-stem elongation) was also noticed, and this suggests a contribution of transplanting shock, as explained by Pandey et al. (2000) and Kumar and Ladha (2011), whereby TP rice experiences shock because of the uprooting process, which is visible due to the subsequent delay in tillering.

WDS rice had a lower $\mathrm{dB}$ during establishment (in $\mathrm{VH}$ ), and a higher $\mathrm{dB}$ during the tillering-stem elongation stage (in VV) as compared to TP rice. A possible explanation is that the low $\mathrm{dB}$ resulted from the dominance of surface scattering from the soil during sowing. The rapid increase of $\mathrm{dB}$ in the tillering-stem elongation stage may correspond to the lack of transplanting shock in WDS allowing the growth process (particularly tillering) to continue without any delay (Pandey et al., 2000; Kumar and Ladha, 2011). Also, in agreement with Lam-Dao et al. (2009), wet and rough soil during the early season, which is due to lower water use in DS, resulted in higher $\mathrm{dB}$ in VV (Fig. 4A).

Another factor is the higher plant density from the larger amount of seeds per hectare in WDS (reported as $35-40 \mathrm{~kg}$ for TP and about $80 \mathrm{~kg}$ for WDS in our farmer interviews). When there are more tillers per unit area, more scattering objects are available, and thus more doublebounce scattering may occur. Furthermore, the rice canopy cover during the tillering to stem elongation stage is not dense and not yet fully developed, so there are still gaps for the SAR signal to penetrate and create double scatterings with the underlying water surface. This finding is consistent with the explanation from Lopez-Sanchez et al. (2014) that the double-bounce scattering in C-band dominates dB during the late vegetative, whereas with the shorter wavelengths, as in $\mathrm{X}$-band, this effect is more visible in the early vegetative. The doublebounce effect is also the biggest contributor to backscatter in VV from the vertically structured crop (Ferrazzoli, 2001) and this may explain the reason why different backscatter values of TP and WDS rice occur at the tillering stage in $\mathrm{VV}$ polarisation. In addition, weed presence in WDS may partially influence the higher $\mathrm{dB}$ in the early growth stages since weed infestation typically occurs almost at the same time as the rice crop emerges from the soil/water (Bordey et al., 2016). Plant distribution may also have an influence on the higher $\mathrm{dB}$ of WDS in the tillering-stem elongation stage. In WDS, seeds are manually broadcasted in the study area (mechanical establishment by drum seeder or seed drill are also possible, but they are not commonly adopted in the 
study area) meaning that there is an uneven distribution of plants across the field. While in TP, seedlings are more evenly distributed (manually or mechanically) which results in wider gaps between plants and fewer scattering interactions.

When the early of tillering stage in WDS was not assumed (supplemental materials), the backscatter of WDS rice at the tillering stage was slightly higher than TP rice which can indicate that tillering was still in process. This is possible because the growth duration may vary depending on other factors such as variety, soil nutrients, climatic and hydrological conditions including rainfall and temperature (Yoshida, 1981). We can still see the differences in backscatter between TP and WDS rice regardless of whether this assumption is used or not, which suggests a good possibility to discriminate between TP and WDS at this stage.

The results from the Mann-Whitney $\mathrm{U}$ tests indicated that TP rice was significantly different from WDS rice during land preparation, crop establishment, and the tillering-stem elongation stages (Table 4). This result was consistent regardless of whether the early tillering assumption in WDS is used or not. Our finding that TP and WDS rice is best discriminated through the observation in the early growing season confirms those obtained by Yang et al. (2014) who investigated the seedling stage as the primary time to distinguish transplanted hybrid rice and direct seeded Japonica rice (by RADARSAT-2, C-band, quad polarimetric data) based on the higher $\mathrm{dB}$ from the seedlings in transplanted rice. We also agree with the results from Gumma et al. (2015) who identified that TP and DS rice have distinct backscatter during transplanting based on C-band RISAT-1 data at HH polarisation. However, our results are the first to identify opportunities to discriminate between TP and WDS across different land management activities and crop stages.

We found that Sentinel-1 images with a high temporal resolution were well suited to monitor and capture the different stages of rice based on evidence from previous literature and observations made in this study. The penetration capability of C-band is particularly advantageous to retrieve information not only from the canopy but also from the underlying soil and water surface before the saturation effect due to full canopy closure (McNairn and Brisco, 2004; Oh et al., 2009) which enables more factors to be considered when interpreting the backscatter signatures at the early rice growth stages. Additionally, the proposed method of relating backscatter to the crop calendar is able to identify differences in backscatter during the entire cropping season in areas with diverse crop calendars.

Most of the observed fields had a regular shape (rectangular but with a narrow width) with field sizes between 0.5 and 2 ha. Average backscatter values were based on a minimum of six or seven $20 \mathrm{~m}$ Sentinel-1 pixels representing the smallest fields in our dataset. Extremely narrow rice fields, with a width of $20 \mathrm{~m}$ or less would be problematic, but this was not an issue in this study area.

A large range of incidence angles will have an effect on the various scattering mechanisms, resulting in a different backscatter. The fields in this study site are located within the central portion of the Sentinel-1 A images, with a narrow range of incidence angles $\left(3^{\circ}\right)$. We did not observe any variation in our results with respect to incidence angle but acknowledge that this would need to be accounted for in larger study sites with a larger range of incidence angles.

\subsection{Limitations, potential applications and recommendations}

This study used multi-temporal SAR intensity information, but other sources of earth observation information can also contribute to the detection of rice crop management practices. For example, the use of SAR coherence (Lopez-Sanchez et al., 2012) data, LiDAR data and spectral and texture information from high-resolution optical sources can also be employed. A multi-sensor approach incorporating two or more of these would likely be the most robust approach for the detection and monitoring of crop management practices.
Our analysis and findings suggest that TP and DS rice in irrigated and rainfed lowland environments can be discriminated using multitemporal Sentinel-1 data, specifically through observations during the early growing season. Our study site is within the major rice-growing region of the Philippines, which represents only a part of the broad range of rice crop and water management practices that take place within diverse rice ecosystems. Further work would need to account for this diversity by testing detection methods in different geographies and rice systems.

Despite the promising results, further studies using ancillary data are encouraged, especially data on tiller density and weed presence to ascertain the contribution of these factors for TP and DS rice discrimination. Gumma et al. (2015) also suggested that weed information can probably help the discrimination process. The inclusion of soil texture information may improve the discrimination due to its relevance to water stagnancy which influences farmer preferences on establishment method (Pandey et al., 2000). Other ancillary data that can be considered are rainfall during land preparation and crop establishment, wage rates as an indicator of economic growth, and employment opportunities in non-farm sectors. All three have been found to significantly affect the adoption of DDS rice in Northeast Thailand (Pandey et al., 2012).

Our study lacked information regarding the homogeneity of fields through the season. Farmer interviews showed that there were no major stress such as droughts or floods in the area, nor was there any report of lodging. Whilst the area is heavily and regularly affected by tropical storms, these occur mainly in the wet season, whereas our study was made during the dry season (since direct seeding is only practised in the dry season in this part of the Philippines). Although weed presence was reported by a few farmers, it was not a prevalent stress, but we acknowledge that weeds would have an impact on the intensity signal, though we were unable to assess this with our data. Weeds are more of a concern in DDS than in WDS and TP rice.

The adopted crop establishment method varies from season to season as some farmers switch from DS to TP depending on agro-climatic and socio-economic conditions (Pandey et al., 2012). The practice of DS, in particular, varies considerably from one location to another in terms of land preparation (tillage), establishment methods, seed rate, water management, weed management, and nutrient management (Kumar and Ladha, 2011) which can result in variation in temporal backscatter and widespread of backscatter values as observed in this study at land preparation and flooding period (Fig. 4A-B). Multilocation and multi-year studies will contribute to a more robust approach to detect crop establishment practices with SAR.

Due to limited samples, we were not able to observe the temporal signature of the backscatter of DDS. Based on the MISTIG survey data, we expected to interview a sufficient number of farmers who practised DDS. However, farmers reported that they stopped DDS shortly after the survey due to severe weed problems and instead shifted to WDS. Projections suggest that DDS will likely be a major practice in many countries in the future (Kumar and Ladha, 2011; IRRI et al., 2018), hence similar studies should be conducted in areas where DDS is practised, ideally with TP and WDS also being present in the same season. This rapid change in practice also suggests that maps of management practice need to be updated frequently, on a seasonal or yearly basis for example.

The wider adoption of DS (either dry or wet seeding) can have implications for many remote sensing-based rice detection techniques. Most rice detection algorithms that use either SAR data (Choudhury and Chakraborty, 2006; Oh et al., 2009; Nelson et al., 2014) or a combination of vegetation and water indices in optical data (Xiao et al., 2002, 2006; Nguyen et al., 2012; Boschetti et al., 2014) depend on a strong water signal during the early season, which is typical of transplanted rice. Direct seeding has a shorter period of flooding and a lower water level in the early season (Bouman et al., 2007; Bouvet and Le Toan, 2011; Kumar and Ladha, 2011) that can result in a weaker water 
signal. Thus, more information on the impacts of crop establishment methods (as well as other management practices) on the temporal rice signature is required to improve the robustness of these rice mapping algorithms across diverse rice ecosystems. This should involve the simultaneous analysis of more than one source of earth observation data. Finally, our approach is based on field level interpretation of averaged SAR intensity information as opposed to methods that rely on pixel level information. We used field level information for this study since the smallest management unit at which crop establishment methods can be are applied is at the field level. Other crop management practices, such as fertilizer application may vary within a field, but crop establishment method does not. We measured the field boundaries using GPS coordinates from the field corners, but this would not be possible to scale for larger areas, or more frequent monitoring should boundaries change over time. This implies that other methods to map field boundaries are required for field-level classification of crop management practices. Access to very high-resolution imagery through the season and in the off season, coupled with machine learning or segmentation approaches and a sufficient ground truth data across diverse agricultural landscapes would be one approach to generate field boundary information every season for crop mapping and monitoring.

\section{Conclusions}

Remote sensing-based detection of two commonly practised rice establishment methods - transplanting and direct seeding - can help understand where they have been practised and whether there are changes in practices over time. In this study, we exploited a dense time series of C-band Sentinel-1 imagery, in conjunction with field observations, and farmer surveys to better understand the temporal backscatter signatures of transplanted and wet direct seeded rice during the dry season in a major rice-growing region of the Philippines. Our results showed that there are differences between the two practices that can be detected from C-band co-polarisation, cross-polarisation and polarisation ratio information during the early growing season, especially during land preparation, crop establishment, and the tillering and stem elongation stages. These findings indicate more opportunity for crop establishment detection by SAR data compared to those in previous studies. More routine detection of rice crop establishment methods requires data on crop establishment date and field boundaries to permit field-level classification in an operational mapping context. In the future, with freely available global coverage and regular observation facilitated by the Sentinel-1 mission, more investigations in larger rice cultivation areas under different management practices, across seasons, and environments are encouraged to assess the reliability and consistency of detection rice establishments through SAR data. Expansion of DS is expected in the future, and this study suggests that its expansion can be mapped but also that existing mapping algorithms may need improvement for accurate mapping of rice areas where DS is practised.

\section{Acknowledgements}

The authors are thankful to farmers and the barangay officials in Central Luzon who participated in the survey. We thank the International Rice Research Institute (IRRI) for the MISTIG data and research collaboration. We thank Dr Eduardo Jimmy P. Quilang, Sonia Asilo, and Rose Mabalay at the PhilRice Central Experiment Station (CES) in Muñoz, Nueva Ecija, Philippines for supporting our stay at the CES during the survey and their advice for our study. Our special thanks to Sravan Shrestha, Kuan Chai, Neale Paguirigan, and Ronald Castro for their help in the field data collection. V N. Fikriyah is grateful for the financial support given by Indonesia Endowment Fund for Education (LPDP) and ITC, University of Twente, and also to IRRI Education for facilitating her internship at IRRI during the fieldwork.

\section{References}

Asilo, S., de Bie, K., Skidmore, A., Nelson, A., Barbieri, M., Maunahan, A., 2014. Complementarity of two rice mapping approaches: characterizing strata mapped by hypertemporal MODIS and rice paddy identification using multitemporal SAR. Remote Sens. 6, 12789-12814. https://doi.org/10.3390/rs61212789.

Bégué, A., Arvor, D., Bellón, B., Betbeder, J., de Abelleyra, D., Ferraz, R.P.D., Lebourgeois, V., Lelong, C., Simões, M., Verón, S.R., 2018. Remote sensing and cropping practices: a review. Remote Sens. 10, 1-32. https://doi.org/10.3390/rs10010099.

Bordey, F.H., Moya, P.F., Beltran, J.C., Dawe, D.C., 2016. Competitiveness of Philippine Rice in Asia. Philippine Rice Research Institute, IRRI, City of Munoz (Philippines).

Boschetti, M., Nutini, F., Manfron, G., Brivio, P.A., Nelson, A., 2014. Comparative Analysis of Normalised Difference Spectral Indices Derived from MODIS for Detecting Surface Water in Flooded Rice Cropping Systems. PLoS One 9. https://doi.org/10. 1371/journal.pone.0088741.

Bouman, Ba.M., Lampayan, R.M., Tuong, T.P., 2007. Water Management in Irrigated Rice: Coping With Water Scarcity, International Rice Research Institute. International Rice Research Institute (IRRI), Los Banos, Philippines.

Bouvet, A., Le Toan, T., 2011. Use of ENVISAT/ASAR wide-swath data for timely rice fields mapping in the Mekong River Delta. Remote Sens. Environ. 115, 1090-1101. https://doi.org/10.1016/j.rse.2010.12.014.

Bouvet, A., Le Toan, T., Lam-Dao, N., 2009. Monitoring of the rice cropping system in the Mekong Delta using ENVISAT/ASAR dual polarization data. IEEE Trans. Geosci Remote Sens. 47, 517-526. https://doi.org/10.1109/TGRS.2008.2007963.

Chakraborty, M., Manjunath, K.R., Panigrahy, S., Kundu, N., Parihar, J.S., 2005. Rice crop parameter retrieval using multi-temporal, multi-incidence angle Radarsat SAR data. ISPRS J. Photogramm. Remote Sens. 59, 310-322. https://doi.org/10.1016/j. isprsjprs.2005.05.001.

Chakraborty, M., Panigrahy, S., Sharma, S.A., 1997. Discrimination of rice crop grown under different cultural practices using temporal ERS-1 synthetic aperture radar data. ISPRS J. Photogramm. Remote Sens. 52, 183-191.

Chauhan, B.S., Hussain Awan, T., Bernard Abugho, S., Evengelista, G., 2015. Effect of crop establishment methods and weed control treatments on weed management, and rice yield. Field Crop. Res. 172, 72-84. https://doi.org/10.1016/j.fcr.2014.12.011.

Chen, C., Quilang, E.J.P., Alosnos, E.D., Finnigan, J., 2011. Rice area mapping, yield, and production forecast for the province of Nueva Ecija using RADARSAT imagery. Can. J. Remote Sens. 37, 1-16. https://doi.org/10.5589/m11-024.

Chen, C.F., Son, N.T., Chen, C.R., Chang, L.Y., Chiang, S.H., 2016. Rice crop mapping using Sentinel-1A phenological metrics. The International Archives of the Photogrammetry, Remote Sensing and Spatial Information Sciences. https://doi.org/ 10.5194/isprsarchives-XLI-B8-863-2016.

Choudhury, I., Chakraborty, M., 2006. SAR signature investigation of rice crop using RADARSAT data. Int. J. Remote Sens. 27, 519-534. https://doi.org/10.1080/ 01431160500239172.

Clauss, K., Ottinger, M., Kuenzer, C., 2018. Mapping rice areas with Sentinel-1 time series and superpixel segmentation. Int. J. Remote Sens. 39, 1399-1420. https://doi.org/ 10.1080/01431161.2017.1404162.

Dong, J., Xiao, X., 2016. Evolution of regional to global paddy rice mapping methods: a review. ISPRS J. Photogramm. Remote Sens. 119, 214-227. https://doi.org/10.1016/ j.isprsjprs.2016.05.010.

European Space Agency (ESA), 2013. ESA Sentinel 1 Handbook, European Space Agency Technical Note. https://doi.org/10.1017/CBO9781107415324.004.

FAO, 2014. A Regional Rice Strategy for Sustainable Food Security in Asia and The Pacific Final Edition. Food and Agriculture Organization of the United Nations, Bangkok.

Farooq, M., Siddique, K.H.M., Rehman, H., Aziz, T., Lee, D.J., Wahid, A., 2011. Rice direct seeding: experiences, challenges and opportunities. Soil Tillage Res. 111, 87-98. https://doi.org/10.1016/j.still.2010.10.008.

Ferrazzoli, P., 2001. SAR for agricullture. 3rd International Symposium' Retrieval of Bioand Geophysical Parameters from SAR Data for Land Applications.

Gumma, M.K., Thenkabail, P.S., Maunahan, A., Islam, S., Nelson, A., 2014. Mapping seasonal rice cropland extent and area in the high cropping intensity environment of Bangladesh using MODIS $500 \mathrm{~m}$ data for the year 2010. ISPRS J. Photogramm. Remote Sens. 91, 98-113. https://doi.org/10.1016/j.isprsjprs.2014.02.007.

Gumma, M.K., Uppala, D., Mohammed, I.A., Whitbread, A.M., Mohammed, I.R., 2015. Mapping direct seeded rice in Raichur District of Karnataka, India. Photogramm. Eng. Remote Sens. 81, 873-880.

Hoang, H.K., Bernier, M., Duchesne, S., Tran, Y.M., 2016. Rice mapping using RADARSAT-2 dual- and quad-pol data in a complex land-use watershed: Cau River Basin (Vietnam). IEEE J. Sel. Top. Appl. Earth Obs. Remote Sens. 9, 3082-3096. https://doi.org/10.1109/JSTARS.2016.2586102.

Inoue, Y., Kurosu, T., Maeno, H., Uratsuka, S., Kozu, T., Dabrowska-Zielinska, K., Qi, J., 2002. Season-long daily measurements of multifrequency (Ka, Ku, X, C, and L) and full-polarization backscatter signatures over paddy rice field and their relationship with biological variables. Remote Sens. Environ. 81, 194-204.

Inoue, Y., Sakaiya, E., 2013. Relationship between X-band backscattering coefficients from high-resolution satellite SAR and biophysical variables in paddy rice. Remote Sens. Lett. 4, 288-295. https://doi.org/10.1080/2150704X.2012.725482.

Inoue, Y., Sakaiya, E., Wang, C., 2014. Capability of C-band backscattering coefficients from high-resolution satellite SAR sensors to assess biophysical variables in paddy rice. Remote Sens. Environ. 140, 257-266. https://doi.org/10.1016/j.rse.2013.09. 001.

IRRI, 2018. IRRI Eyes Public-private Sector Support for Wider DSR Adoption [WWW Document]. URL. (Accessed 9 February 2018). http://irri.org/news/mediareleases/irri-eyes-public-private-sector-support-for-wider-dsr-adoption.

IRRI, 2007a. Transplanting [WWW Document]. URL. (Accessed 14 June 2018). http:// 
www.knowledgebank.irri.org/ericeproduction/II.4_Transplanting.htm.

IRRI, 2007b. Direct Seeding [WWW Document]. URL. (Accessed 14 June 2018). http:// www.knowledgebank.irri.org/ericeproduction/II.3_Direct_seeding.htm.

IRRI, 2007c. 0.2 Growth Stages of the Rice Plant [WWW Document]. URL. (Accessed 17 August 2017). http://www.knowledgebank.irri.org/ericeproduction/0.2._Growth_ stages of the rice plant.htm.

Koppe, W., Gnyp, M.L., Hütt, C., Yao, Y., Miao, Y., Chen, X., Bareth, G., 2013. Rice monitoring with multi-temporal and dual-polarimetric TerraSAR-X data. Int. J. Appl. Earth Obs. Geoinf. 21, 568-576. https://doi.org/10.1016/j.jag.2012.07.016.

Kuenzer, C., Knauer, K., 2013. Remote sensing of rice crop areas. Int. J. Remote Sens. 34, 2101-2139. https://doi.org/10.1080/01431161.2012.738946.

Kumar, V., Ladha, J.K., 2011. Direct Seeding of Rice. Recent Developments and Future Research Needs, 1st ed. Advances in Agronomy. Elsevier Inc., New Delhi. https://doi. org/10.1016/B978-0-12-387689-8.00001-1.

Kurosu, T., Fujita, M., Chiba, K., 1995. Monitoring of rice crop growth from space using the ERS-1 C-band SAR. IEEE Trans. Geosci. Remote Sens. 33, 1092-1096. https://doi. org/10.1109/36.406698.

Lam-Dao, N., Le Toan, T., Apan, A., Bouvet, A., Young, F., Le-Van, T., 2009. Effects of changing rice cultural practices on C-band synthetic aperture radar backscatter using Envisat advanced synthetic aperture radar data in the Mekong River Delta. J. Appl. Remote Sens. 3, 033563. https://doi.org/10.1117/1.3271046.

Lavreniuk, M., Kussul, N., Meretsky, M., Lukin, V., Abramov, S., Rubel, O., 2017. Impact of SAR data filtering on crop classification accuracy. IEEE First Ukraine Conference on Electrical and Computer Engineering (UKRCON). pp. 912-916.

Le Toan, T., Ribbes, F., Wang, Li-Fang, Floury, N., Ding, Kung-Hau, Kong, Jin Au, Fujita, M., Kurosu, T., 1997. Rice crop mapping and monitoring using ERS-1 data based on experiment and modeling results. IEEE Trans. Geosci. Remote Sens. 35, 41-56. https://doi.org/10.1109/36.551933.

Lopez-Sanchez, J.M., Cloude, S.R., Ballester-Berman, J.D., 2012. Rice phenology monitoring by means of SAR polarimetry at X-band. IEEE Trans. Geosci. Remote Sens. 50, 2695-2709. https://doi.org/10.1109/TGRS.2011.2176740.

Lopez-Sanchez, J.M., Vicente-Guijalba, F., Ballester-Berman, J.D., Cloude, S.R., 2014 Polarimetric response of rice fields at C-band: analysis and phenology retrieval. IEEE Trans. Geosci. Remote Sens. 52. https://doi.org/10.1109/TGRS. 2013.2268319.

Mansaray, L.R., Huang, W., Zhang, D., Huang, J., Li, J., 2017. Mapping rice fields in urban Shanghai, southeast China, using Sentinel-1A and Landsat 8 datasets. Remote Sens. 9. https://doi.org/10.3390/rs9030257.

McCrum-Gardner, E., 2008. Which is the correct statistical test to use? Br. J. Oral Maxillofac. Surg. 46, 38-41. https://doi.org/10.1016/j.bjoms.2007.09.002.

McNairn, H., Brisco, B., 2004. The application of C-band polarimetric SAR for agriculture: a review. Can. J. Remote Sens. 30 (3), 525-542.

McNairn, H., Shang, J., 2016. A review of multitemporal synthetic aperture radar (SAR) for crop monitoring. In: Ban, Y. (Ed.), Multitemporal Remote Sensing. Springer, Cham, pp. 317-340. https://doi.org/10.1007/978-3-319-47037-5 15.

Mosleh, M.K., Hassan, Q.K., Chowdhury, E.H., 2015. Application of remote sensors in mapping rice area and forecasting its production: a review. Sensors (Switzerland) 15, 769-791. https://doi.org/10.3390/s150100769.

Moya, P., Kajisa, K., Barker, R., Mohanty, S., Gascon, F., Valentin, M.R.S., 2015. Changes in Rice Farming in the Philippines: Insights From Five Decades of a Household-level Survey. International Rice Research Institute, Los Banos, Philippines.

Nelson, A., Setiyono, T., Rala, A., Quicho, E., Raviz, J., Abonete, P., Maunahan, A., Garcia, C., Bhatti, H., Villano, L., Thongbai, P., Holecz, F., Barbieri, M., Collivignarelli, F., Gatti, L., Quilang, E., Mabalay, M., Mabalot, P., Barroga, M., Bacong, A., Detoito, N., Berja, G., Varquez, F., Wahyunto, E., Kuntjoro, D., Murdiyati, S., Pazhanivelan, S., Kannan, P., Mary, P., Subramanian, E., Rakwatin, P., Intrman, A., Setapayak, T., Lertna, S., Minh, V., Tuan, V., Duong, T., Quyen, N., Van Kham, D., Hin, S., Veasna, T., Yadav, M., Chin, C., Ninh, N., 2014. Towards an operational SAR-based rice monitoring system in Asia: examples from 13 demonstration sites across Asia in the RIICE project. Remote Sens. 6, 10773-10812. https://doi.org/10.3390/rs61110773.

Nguyen, D., Clauss, K., Cao, S., Naeimi, V., Kuenzer, C., Wagner, W., 2015. Mapping rice seasonality in the Mekong Delta with multi-year envisat ASAR WSM data. Remote Sens. 7, 15868-15893. https://doi.org/10.3390/rs71215808.

Nguyen, D.B., Gruber, A., Wagner, W., 2016. Mapping rice extent and cropping scheme in the Mekong Delta using Sentinel-1A data. Remote Sens. Lett. 7, 1209-1218. https:// doi.org/10.1080/2150704X.2016.1225172.

Nguyen, D.B., Wagner, W., 2017. European rice cropland mapping with Sentinel-1 data: the Mediterranean region case study. Water (Switzerland) 9, 1-21. https://doi.org/ 10.3390/w9060392.

Nguyen, T.T.H., Bie, C.A.J.M.De, Ali, A., Smaling, E.M.A., Thu, T., Nguyen, H., Bie, C.A.J.M.De, Ali, A., Smaling, E.M.A., 2012. Mapping the irrigated rice cropping patterns of the Mekong delta, Vietnam, through hyper-temporal SPOT NDVI image analysis. Int. J. Remote Sens. 33, 415-434. https://doi.org/10.1080/01431161.2010. 532826.

Oh, Y., Hong, S.Y., Kim, Y., Hong, J.Y., Kim, Y.H., 2009. Polarimetric backscattering coefficients of flooded rice fields at L- and C-bands: measurements, modeling, and data analysis. IEEE Trans. Geosci. Remote Sens. 47, 2714-2721. https://doi.org/10 1109/TGRS.2009.2014053.

Pandey, S., Mortimer, A.M., Wade, L., Tuong, Tp., Lopez, K., Hardy, B., 2000. Direct seeding:research issues and opportunities. Proceedings of the International Workshop on Direct Seeding in Asian Rice Systems:Strategic rEsearch Issues and OppoRtunities 2.

Pandey, S., Suphanchaimat, N., Velasco, M.L., 2012. The patterns of spread and economics of a labor-saving innovation in rice production: the case of direct seeding in Northeast Thailand. Q. J. Int. Agric. 51, 333-356.

Ray, D.K., Ramankutty, N., Mueller, N.D., West, P.C., Foley, J.A., 2012. Recent patterns of crop yield growth and stagnation. Nat. Commun. 3, 1293-1297. https://doi.org/10. 1038/ncomms2296.

Sangeetha, C., Baskar, P., 2015. Influence of different crop establishment methods on productivity of rice-A Review. Agri. Rev. 36, 113-124. https://doi.org/10.5958/ 0976-0741.2015.00013.6.

Sarabandi, K., Oh, Y., Ulaby, F.T., 1991. Polarimetric radar measurements of bare soil surfaces at microwave frequencies. Geosci. Remote Sens. Symp. 1991. IGARSS'91. Remote Sens. Glob. Monit. Earth Manag. Int. 2, 387-390. https://doi.org/10.1109/ IGARSS.1991.579162.

Setiyono, T.D., Holecz, F., Khan, N.I., Barbieri, M., Quicho, E., Collivignarelli, F., Maunahan, A., Gatti, L., Romuga, G.C., 2017. Synthetic Aperture Radar (SAR)-based paddy rice monitoring system: development and application in key rice producing areas in Tropical Asia. IOP Conf. Ser. Earth Environ. Sci. 54, 012015. https://doi.org/ 10.1088/1755-1315/54/1/012015.

Shao, Y., Fan, X., Liu, H., Xiao, J., Ross, S., Brisco, B., Brown, R., Staples, G., 2001. Rice monitoring and production estimation using multitemporal RADARSAT. Remote Sens. Environ. 76, 310-325.

Singh, Y., Singh, V.P., Chauhan, B., Orr, A., Mortimer, A.M., Johnson, D.E., Hardy, B., 2008. Direct Seeding of Rice and Weed Management in the Irrigated Rice-Wheat Cropping System of the Indo-Gangetic Plains. International Rice Research Institute (IRRI), Los Banos (Philippines).

Singh, Y., Singh, V.P., Singh, G., Yadav, D.S., Sinha, R.K.P., Johnson, D.E., Mortimer, A.M., 2011. The implications of land preparation, crop establishment method and weed management on rice yield variation in the rice-wheat system in the IndoGangetic plains. F. Crop. Res. 121, 64-74. https://doi.org/10.1016/j.fcr.2010.11. 012.

Sudhir-Yadav, Evangelista, G., Faronilo, J., Humphreys, E., Henry, A., Fernandez, L., 2014. Establishment method effects on crop performance and water productivity of irrigated rice in the tropics. Field Crop. Res. 166, 112-127. https://doi.org/10.1016/ j.fcr.2014.06.001.

Torbick, N., Chowdhury, D., Salas, W., Qi, J., 2017. Monitoring rice agriculture across myanmar using time series Sentinel-1 assisted by Landsat-8 and PALSAR-2. Remote Sens. 9. https://doi.org/10.3390/rs90201019.

Xiao, X., Boles, S., Frolking, S., Li, C., Babu, J.Y., Salas, W., Moore, B., 2006. Mapping paddy rice agriculture in South and Southeast Asia using multi-temporal MODIS images. Remote Sens. Environ. 100, 95-113. https://doi.org/10.1016/j.rse.2005.10. 004.

Xiao, X., Boles, S., Frolking, S., Salas, W., Moore Iii, B., Li, C., He, L., Zhao, R., 2002. Observation of flooding and rice transplanting of paddy rice fields at the site to landscape scales in China using VEGETATION sensor data. Int. J. Remote Sens. 23, 143-1161. https://doi.org/10.1080/01431160110107734.

Yang, Z., Li, K., Liu, L., Shao, Y., Brisco, B., Li, W., 2014. Rice growth monitoring using simulated compact polarimetric C band SAR. Radio Sci. 49, 1300-1315. https://doi. org/10.1002/2014RS005498.

Yang, Z., Yun, S., Kun, L., Qingbo, L., Long, L., Brisco, B., 2017. An improved scheme for rice phenology estimation based on time-series multispectral HJ-1A/B and polarimetric RADARSAT-2 data. Remote Sens. Environ. 195, 184-201. https://doi.org/10. 1016/j.rse.2017.04.016.

Yoshida, S., 1981. Fundamentals of Rice Crop Science, Fundamentals of Rice Crop Science. International Rice Research Institute (IRRI), Los Banos (Philippines).

Zhang, G., Xiao, X., Dong, J., Kou, W., Jin, C., Qin, Y., Zhou, Y., Wang, J., Menarguez, M.A., Biradar, C., 2015. Mapping paddy rice planting areas through time series analysis of MODIS land surface temperature and vegetation index data. ISPRS J. Photogramm. Remote Sens. 106, 157-171. https://doi.org/10.1016/j.isprsjprs.2015. 05.011 . 